\title{
Corn Harvester Cutting Table with Adjustable Spacing
}

\author{
Chong WANG *1,a, Shu-kun CAO ${ }^{2, b}$, Chang-zhong WU \\ Sheng-nan WANG and Ying-ying ZHAO \\ ${ }^{1}$ School of Mechanical Engineering, University of Jinan, Jinan, Shandong, 250000, China, I mainly \\ engage in the research and the development of intelligent corn harvester. \\ ${ }^{2}$ Shu-kun CAO, School of Mechanical Engineering, University of Jinan, Jinan, Shandong, 250000, \\ China, I mainly engage in the intelligent agricultural machinery and intelligent manufacturing. \\ a535756212@qq.com b87756997@qq.com
}

Keywords: corn harvester, agricultural machinery, adjustable row spacing, folding, image recognition

\begin{abstract}
Mechanical harvest of corn can greatly improve the efficiency of harvesting. Corn harvester have to adapt to different regions of China's growing habits, such as different row spacing and plant spacing. The improvement of harvesting efficiency depends on the continuous innovation and improvement of the design of the cutting table. This cutting table can be folded and adjust row space, and thus solved the current technical problems of corn harvester. Compared with the traditional cutting table, the harvest efficiency increased by $50 \%$. The design will achieve a major breakthrough in the corn harvester industry.
\end{abstract}

\section{INTRODUCTION}

The corn harvester cutting table is a key part which impact the efficiency directly. At present, cutting table has 1 lines to 5 lines in the market [1].The bigger the row number, the more bulky the cutting table. Walking and transportation are not convenient. For high strength requirements [2]. So most manufacturers choose to carry out mass production within 5 lines. At present corn harvest technology in foreign countries developed rapidly and the technology is more mature. The largest combine harvester is produced by Caterpillar, the model is Lexion 590R. It can be used to harvest corn, rice, wheat, and any other crops. It can harvest 2832 liters of grain per minute. And this record cannot be broken up to now [3]. Agricultural machinery products toward large-scale, intelligent development, which is a new challenge for the development of China's corn harvest machine [4].

\section{STRUCTURE OF THE WHOLE SYSTEM AND ITS OPERATIONAL PRINCIPLE}

\section{General Structure}

As shown in Figure 1, the new corn harvester cutting table is mainly composed of cutting table supporting frame, folding mechanism, 9 groups of snapping roll combination, guide, slider, auger and hydraulic cylinder. The guide rail is arranged on the cutting table frame. 9 groups of snapping roll combination is arranged on the guide rail. A hydraulic cylinder is arranged between the two sets of snapping roll combination. Cutting table frame is divided into three parts. Each of them connected through a folding mechanism. The folding mechanism is connected with the support frame through the hydraulic cylinder and the middle cutting table. The auger is divided into three sections, and each section corresponds to a part of the cutting table frame. 


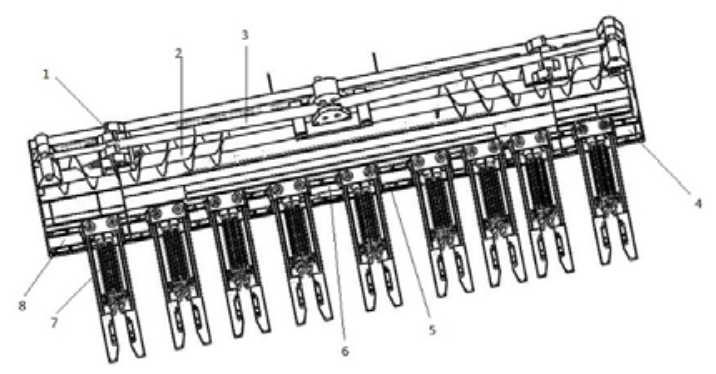

1-Folding mechanism; 2- Auger; 3- Hydraulic cylinder; 4- The right part of the support frame; 5- Guide; 6- The middle part of the support frame; 7-Combination of snapping roll; 8-The left part of the support frame

Figure 1. Integral structure of cutting table

Each snapping roll is powered by a hydraulic motor, and so as the auger. Because the cutting table is folding structure. So auger need to achieve separate without affecting the normal operation of the state. Therefore, the spherical gear coupling is used at the connection point of every two sections. The folding structure is shown in Figure 2. The design of this structure is satisfied that each part does not interfere with each other.

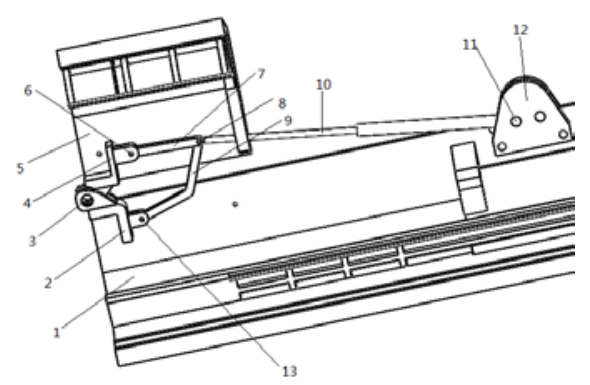

1- The middle part of the support frame; 2- Connecting hole seat 1; 3- Pin 5; 4- Connecting hole seat 2; 5- The left part of the support frame; 6- Pin 1; 7- Connecting arm 1; 8-pin 2; 9- Connecting arm 2; 10- Hydraulic cylinder; 11- Pin 4; 12- Hydraulic cylinder support frame; 13-Pin 3

Figure 2. Folding structure of cutting table

\section{Working Principle}

The intelligent cutting station was placed on the guide rail. Due to the thrust of the intermediate hydraulic cylinder, that can achieve spacing adjustment. Through the installation of the camera in the cutting table to determine the location of corn plants in the field. Automatic adjustment of the line diagram were shown in Figure 3 and Figure 4. Sensors are placed at the front of the cutting table, which can able to accurately adjust the height based on the feedback data. The hydraulic motors connect the snapping roll and reel chain through the gearbox, so that snapping roll and reel chain can adjust the speed in real time. The cutting table is designed in 9 rows and can be folded by the thrust of the hydraulic cylinder.

\section{THE DISTANCE DISCRIMINANT ANALYSIS BASED ON IMAGE RECOGNITION}

This design uses image recognition to identify the maize plants. The test using type MV-EM510M industrial camera and type M0824-MPW2 Industrial lens. Image processing software using Lab VIEW. 
The color of each pixel in a color image is determined by the three components $\mathrm{R}, \mathrm{G}$ and $\mathrm{B}$. Grayscale image is a kind of special color image which contains $R, G$ and $B$ three identical components. There are 255 kinds of changes in one pixel. In RGB model, if $R=G=B$, then the color represents a gray color, where $R=G=B$ value is called the gray value. In the model, if $R=G=B$, color represents a type of gray color, and the value of $\mathrm{R}=\mathrm{G}=\mathrm{B}$ is called gray value [5]. Grayscale image processing generally have three methods: Weighted average method, mean value method and maximum method [6]. In the Lab VIEW software platform, the gray level of the image processing only need to use the visual assistant module. Next is the image enhancement, this step selected the 3X3 square median filter in order to achieve the desired effect. The next step is dilation and erosion. In the design process, the first option is open operation, which is the first expansion of the process of corrosion. In this paper we selected structural elements of $7 X 7$. Because compared with the structural elements of $3 X 3$ and $5 \times 5$, the structural elements of $7 \times 7$ is more accurate. Next is the binarization of the image. In the Vision of Lab VIEW, there are specialized modules can achieve the function of binarization named "threshold". We chose the adaptive threshold of the moments. The binarized image still has some image information that we do not need. For these useless information, we need to use a certain image segmentation technology. In Vision, there are also have special modules to achieve image segmentation. Thus, the whole image preprocessing is completed, and the feature extraction and matching are carried out. The position of the corn plant and the position of the center coordinates are shown in Figure 3 and Figure4.

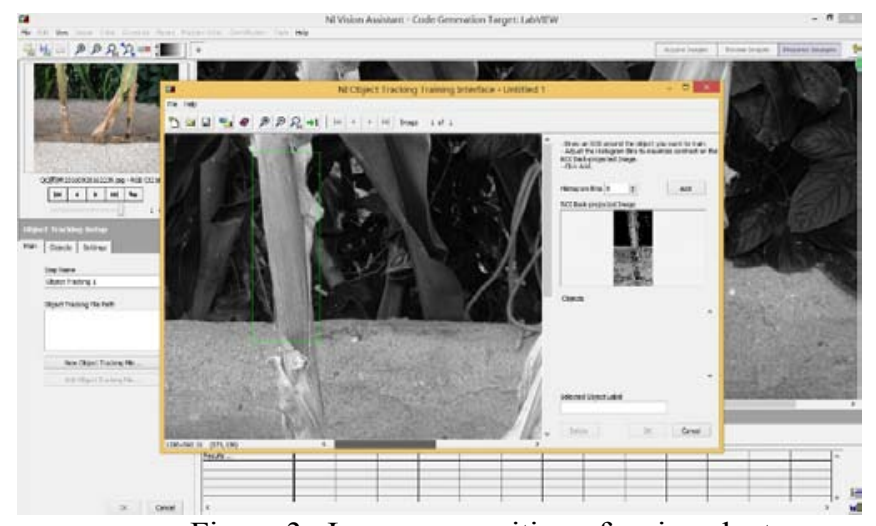

Figure 3. Image recognition of maize plants

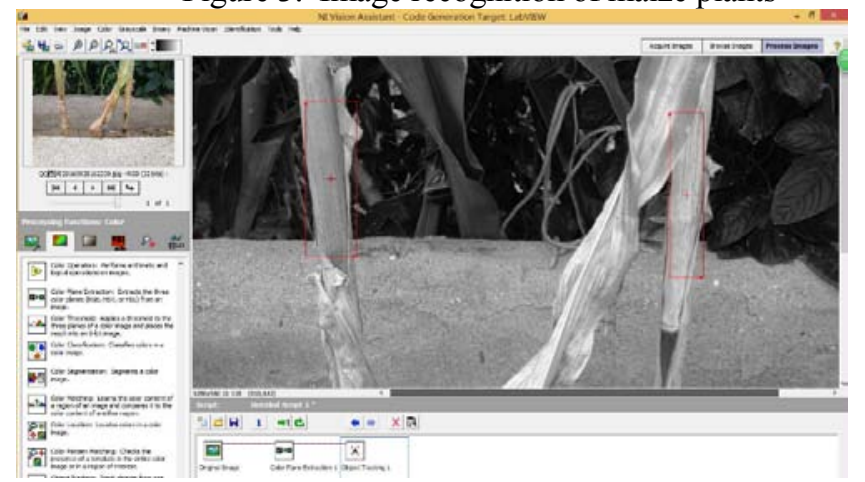

Figure 4. Maize plant central location

\section{SUMMARY}

In this paper, we designed a kind of harvester cutting machine which can adjust the distance between crops [7]. It can solve the problems of not adapt to farmers' different planting habit and low harvesting efficiency and low intelligence level. And the adjustment of the line spacing can be realized intelligently. 
We use the advanced image recognition technology to identify the maize plant location and determine the row spacing, so that snapping roll can automatically adjust the spacing according to the different row spacing in different planting area without human intervention. In view of the shortcomings of the cutting table width is too large, the structure of the cutting platform can be folded. In this paper, the structure of the corn harvester cutting table is transformed, which greatly improves the harvest intelligence and harvest efficiency.

\section{ACKNOWLEDGEMENTS}

This work was financially supported by Shandong Province Science and Technology Major Special (2015ZDZX10001) and Taishan Industry Leading Talent Project Special Funds.

\section{REFERENCES}

1. XU Changhai. Problems and suggestions on mechanization of maize harvesting in Hulun Buir city [J]. Rural and Pastoral Areas Mechanization, 2012,01:28-30.

2. XIE Qiong, ZHANG Huiquan, LIU Lin. Current situation and Prospect of the development of maize harvesting mechanization in China [J]. Agricultural Science and Technology and Equipment, 2009,06:104-106.

3. ZHANG Xiaodong, SHENG Guocheng. Introduction of several corn harvesting machinery [J]. Agricultural Development and Equipment, 2010,10:38-39.

4. QI Wanhua, ZHAO Qinglai. The adaptability of corn harvester design [J]. Technology Consulting Herald, 2007,20:241.

5. CHEN Qingfeng. Image processing method for identifying the trunk of an orange [D]. Jiangsu University, 2009

6. ZHANG Jiayi. The image recognition technology status and development trend of [J]. computer knowledge and technology, 2010,21:6045-6046.

7. CHEN Yanxin, ZHANG Daolin, XU Zhen, YANG Tingwen. Experiment of the folding type corn harvester cutting table [J]. Agricultural Mechanization Research, 2013,02:117-120. 